\title{
Repression and Activation of Promoter-bound RNA Polymerase Activity by Gal Repressor
}

\author{
Hyon E. Choy ${ }^{1}$, Robert R. Hanger ${ }^{1}$, Tsunehiro Aki ${ }^{1}$, Michael Mahoney ${ }^{1}$ \\ Katsuhiko Murakami ${ }^{2}$, Akira Ishihama ${ }^{2}$ and Sankar Adhya ${ }^{1 *}$
}

\author{
${ }^{1}$ Laboratory of Molecular \\ Biology, National Cancer \\ Institute, National Institutes of \\ Health, Bethesda \\ MD 20892-4255, USA \\ ${ }^{2}$ Department of Molecular \\ Genetics, National Institute of \\ Genetics, Mishima \\ Shizuoka 411, Japan
}

By binding to the DNA site $O_{\mathrm{E}}$ at position -60.5 in the gal operon, the GalR protein activates transcription from the $P 2$ promoter located on the opposite face of DNA (position -5) and represses transcription from the $P 1$ promoter located on the same face (position +1 ). GalR increases RNA polymerase binding at $P 2$ and inhibits isomerization at $P 1$ by forming a GalR-DNA-RNA polymerase ternary complex in each case. The specific effect of GalR at one promoter is independent of the presence of the other promoter. The enhancement or repression is also not the intrinsic property of a promoter; the regulation can be reversed by switching the angular orientation of the promoters relative to $O_{\mathrm{E}}$. Both enhancement and repression appear to require the same interaction between RNA polymerase $\alpha$-subunit and GalR and/or the same interaction between RNA polymerase $\alpha$-subunit and DNA in the ternary complexes. We have discussed how GalR might exert opposite effects in the steps involved in the formation of the open complex from free RNA polymerase and DNA.

Keywords: transcription; RNA polymerase; alpha subunit; repression monstrated that GalR stimulates open complex formation at $P 2$ and inhibits isomerization at $P 1$, and both effects require the presence of the carboxy domain of the $\alpha$-subunit $(\alpha C T D)$ of RNA polymerase (Choy et al., 1995a). Here, we provide evidence that suggests that both repression of $P 1$ and enhancement of $P 2$ by GalR depends upon interactions involving the same amino acid residues in $\alpha$ CTD and we demonstrate the formation of GalR-DNA-RNA polymerase ternary complex at both promoters.

\section{Results}

\section{$\boldsymbol{P 1}$ repression and $\boldsymbol{P} 2$ activation are independent events}

GalR normally represses transcription from the two gal promoters by binding to bipartite operators, $O_{\mathrm{E}}$ and $O_{\mathrm{I}}$, located at position -60.5 and +53.5 , respectively. The two operator-bound GalR molecules associate in the presence of the histonelike protein $\mathrm{HU}$ resulting in the formation of a DNA loop encompassing the promoters (Aki et al., 1996; Aki \& Adhya, 1997). A DNA loop changes the structure of the promoters, making them refractory to RNA polymerase activity (Choy et al., $1995 b)$. In the absence of HU, however, GalR binding to $O_{\mathrm{E}}$ shows different effects on $P 1$ and $P 2$; it represses the former and activates the latter (Choy 


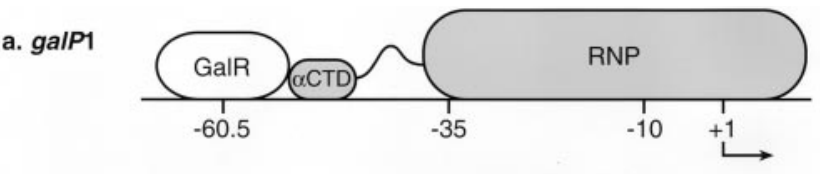

b. galP2

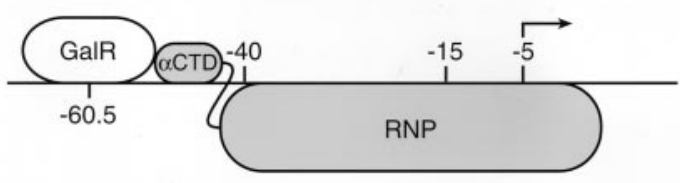

c. lacP

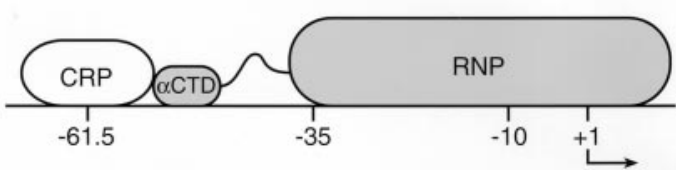

Figure 1. $a$ and $b$, The gal promoter region with the relative position and orientation of GalR and of RNA polymerase at the two gal promoters, $P 1$ and $P 2$. Operator $O_{\mathrm{E}}$, centered at position -60.5 and $O_{\mathrm{I}}$, centered at position +53.5 (not shown), bind GalR. The transcription start sites for $P 1$ and $P 2$ are +1 and -5 , respectively. Note that RNA polymerase binds to either $P 1$ (a) or $P 2$ (b) at a time. c, The lac promoter region with the relative position and orientation of CAMP.CRP and of RNA polymerase. The CAMP.CRP binding site is centered at position -61.5 .

\& Adhya, 1992). Figure 2 shows the typical regulatory effect of GalR bound to $O_{E}$ on transcription initiation. Both the wild-type template $\left(\mathrm{O}^{+} \mathrm{O}_{\mathrm{I}}^{+}\right)$and the template mutated at $\mathrm{O}_{\mathrm{I}}\left(\mathrm{O}_{\mathrm{E}}^{+} \mathrm{O}_{\mathrm{I}}^{-}\right)$showed differential effects of GalR, i.e. $P 2$ activation and $P 1$ repression, whereas the DNA template mutated at $O_{\mathrm{E}}^{-}\left(O_{\mathrm{E}}^{-} \mathrm{O}_{\mathrm{I}}^{+}\right)$eliminated both. To study whether the specific behavior of one gal promoter depends on the other, we tested the effect of GalR on transcription from DNA templates carrying only one promoter and the other mutated, $P 1^{+} P 2^{-}$or $P 1^{-} P 2^{+}$ (Figure 3). As expected from the results presented by Bingham et al. (1986), the mutated promoter abolished the synthesis of the corresponding gal transcript in each case. Only the P1 RNA was synthesized from the $P 1^{+} P 2^{-}$DNA and $P 2$ transcript from the $P 1^{-} P 2^{+}$template. Moreover, increasing concentrations of GalR inhibited the P1 RNA synthesis in the absence of an active $P 2$ promoter (Figure $3 b$ ) and enhanced the $P 2$ transcription in the absence of an active $P 1$ promoter although the $P 2$ enhancement effect was slightly less than that found in the wild-type template (Figure 3c). These results indicated the independence of $P 1$ and $P 2$ in responding to the regulatory effect of GalR. To test whether GalR stimulates $P 2$ by recruiting more RNA polymerase or by stimulating another step, we studied the independent response of the promoters toward $100 \mathrm{nM}$ GalR by varying the RNA polymerase concentration in such experiments (Figure 4). GalR, as expected, inhibited P1 fourfold and stimulated $P 2$ twofold at varying concentrations of RNA polymerase in the wild-type template without reaching maxima up to $20 \mathrm{nM}$ RNA polymerase (Figure $4 \mathrm{a}$ and $\mathrm{b}$ ). GalR stimulated $P 2$ RNA synthesis slightly less, about 1.6-fold, at less than $20 \mathrm{nM}$ RNA polymerase in the DNA template in which the $P 1$ promoter has been mutationally inactivated. The reduction of GalR-mediated stimulation of the $P 2$ promoter is attributed to the fact that P2 RNA synthesis is already higher from the $P 1^{-} P 2^{+}$DNA as compared to that from the wildtype DNA in the absence of GalR; the $P 1$ mutation present in the $P 1^{-} P 2^{+}$DNA has increased $P 2$ RNA synthesis about twofold in an unknown way.
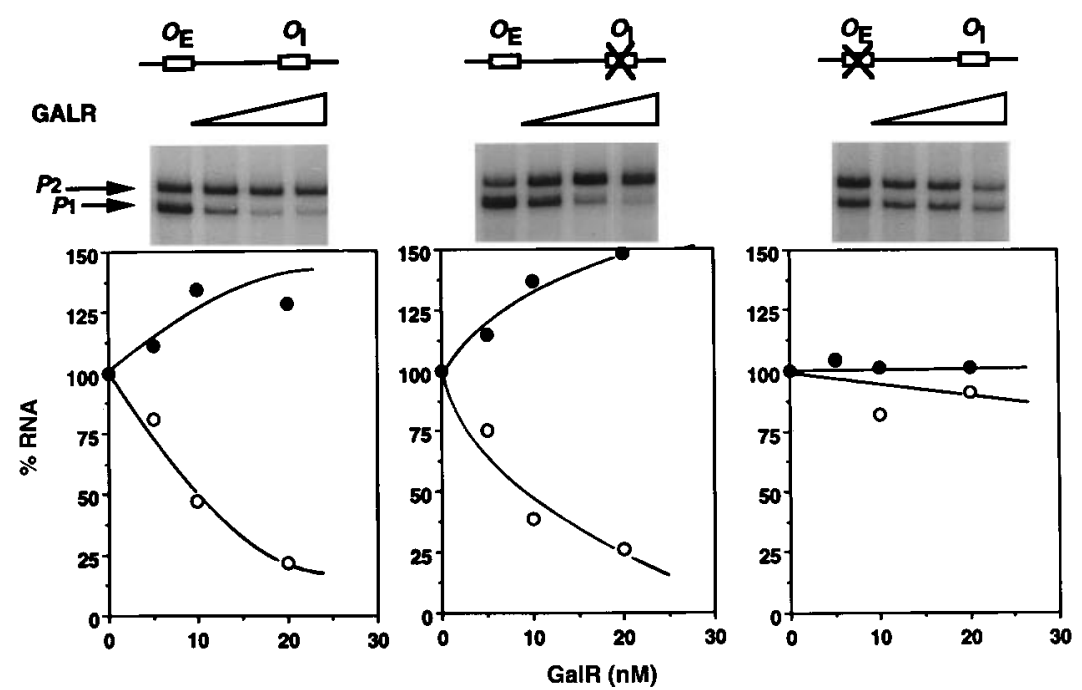

Figure 2. Regulation of gal transcription by GalR. gal transcription was carried out as described in Materials and Methods in the presence of increasing concentrations of GalR using wild-type and mutant DNA templates shown at the top. RNA was resolved on the $8 \%$ gel shown in the middle. The full-length $P 1$ and $P 2$ RNAs are 120 and $125 \mathrm{nt}$ long. GalR binding to an intact $O_{\text {I }}$ operator blocks fulllength RNA synthesis, resulting in the synthesis of shorter, prematurely terminated RNA from $P 1$ and P2 (Choy et al., 1995a; and not shown). Both long and short transcripts were taken into account in quantifying the relative amounts of RNA synthesis as shown in the bottom. Left panel, $\mathrm{O}_{\mathrm{E}}^{+} P 2^{+} P 1^{+} \mathrm{O}_{\mathrm{I}}^{+}$ DNA (pSA510); middle panel, $O_{\mathrm{E}}^{+} P 2^{+} P 1^{+} O_{\mathrm{I}}^{-}$DNA (pSA511); and right panel, $\mathrm{O}_{\mathrm{E}}^{-} P 2^{+} P 1^{+} \mathrm{O}_{\mathrm{I}}^{+}$DNA (pSA512). P2 RNA, filled circles; and P1 RNA, open circles. 


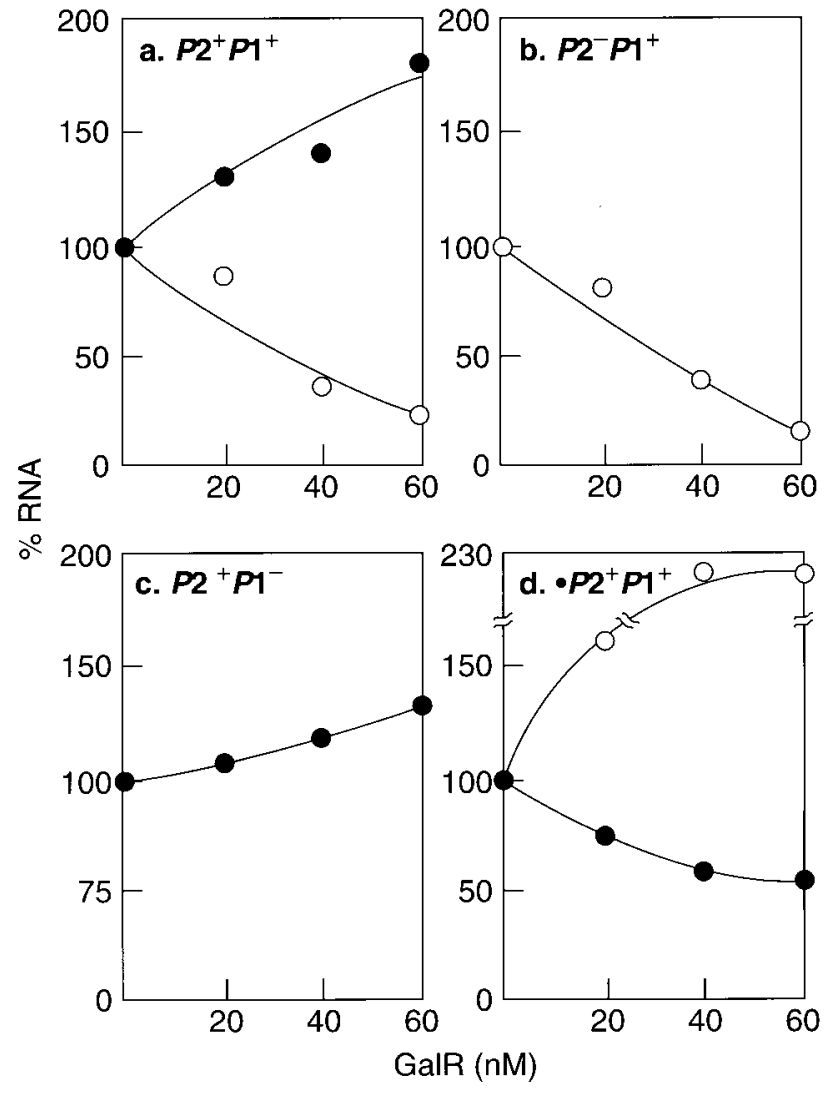

Figure 3. Effect of varying GalR concentrations on different gal promoter mutant DNA templates. Transcriptions were as in the experiments of Figure 2. All templates are of the genotype $O_{\mathrm{E}}^{+} \mathrm{O}_{\mathrm{I}}^{-}$. Relative to the amounts made in the absence of GalR, $P 1$ and P2 RNA were plotted as a function of repressor concentrations. $P 1$, open circles; $P 2$, filled circles. a, Wild-type gal promoters (pSA544); b, $P 2^{-} P 1^{+}$DNA (pSA545); c, $P 2^{+} P 1^{-}$ DNA (pSA546); $d, \bullet P 2^{+} P 1^{+}$DNA but with a 5 bp insertion between $O_{\mathrm{E}}^{+}$and the wild-type promoters (pSA548).

Importantly, at higher RNA polymerase concentrations, GalR stimulation of $P 2$ was insignificant (Figure $4 \mathrm{c}$ and data not shown). In control experiments, the presence of the repressor protein had no effect on the synthesis of RNA1 from the rep promoter, used as a control, at any concentration of RNA polymerase (Figure $4 \mathrm{~d}$ ).

\section{Opposite responses of $P 1$ and $P 2$ to GalR can be reversed}

$P 1$ and $P 2$ are spatially separated by half of a DNA helical turn and thus are on the opposite faces of the cylindrical DNA (Figure 1). Repressor bound to $O_{\mathrm{E}}$ occupies the same face of the helix as the RNA polymerase occupying $P 1$; on the other, repressor bound to $O_{E}$ is on the other side of the RNA polymerase bound to P2 (Majumdar \& Adhya, 1987, 1989; Belyaeva et al., 1996). Using a hybrid gal DNA template, in which the $O_{\mathrm{E}}$ segment was replaced by a lac operator sequence, we pre-

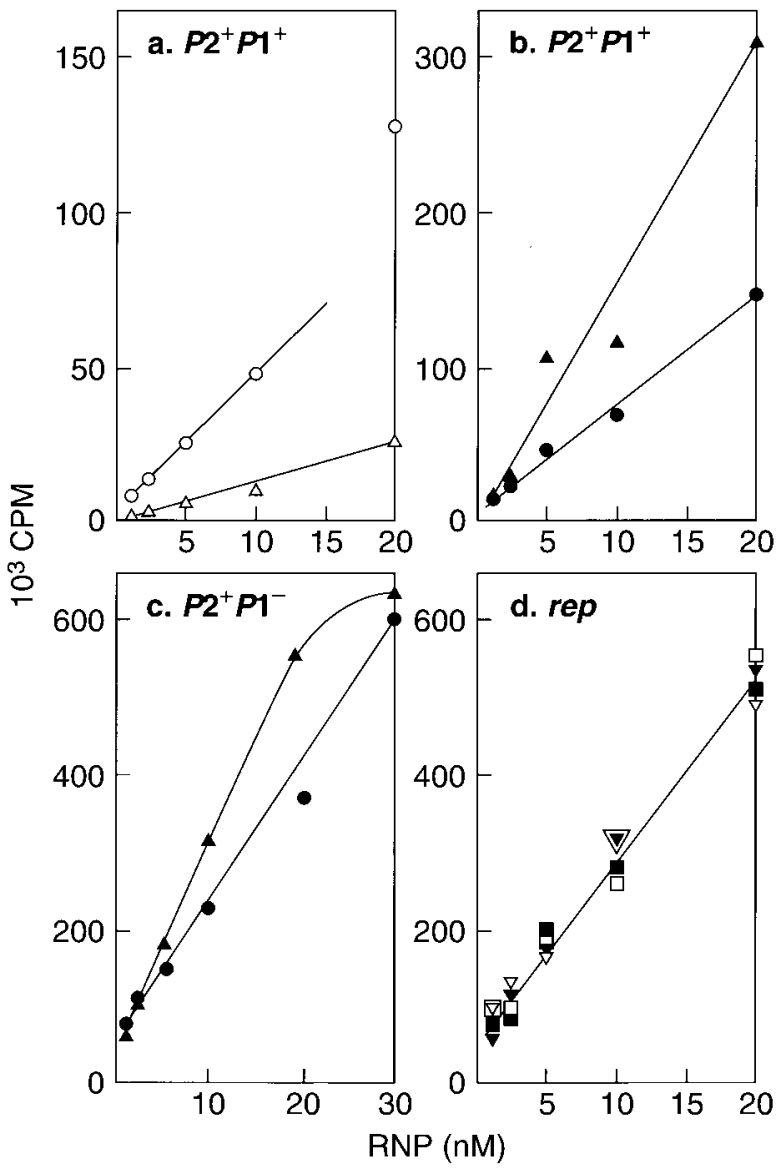

Figure 4. Effect of varying concentrations of RNA polymerase on gal RNA synthesis in the absence and presence of GalR $(100 \mathrm{nM})$. Transcription reactions were as in the experiments of Figure 2. All DNA were of the $O_{\mathrm{E}}^{+} \mathrm{O}_{\mathrm{I}}^{-}$genotype. a, P1 RNA from wild-type promoter (pSA544); b, P2 RNA from wild-type promoter (pSA544); c, $P 2$ RNA from $P 2^{+} P 1^{-}$promoter (pSA546); $\mathrm{d}$, RNA1 made from the rep promoter present in pSA544 and pSA546. Open circles, P1 RNA without GalR and open triangles, $P 1$ RNA with GalR; filled circles, P2 RNA without GalR and filled triangles, P2 RNA with GalR; open squares, RNA1 without GalR and filled squares, RNA1 with GalR from pSA544; open inverted triangles, RNA1 without GalR and filled inverted triangles, RNA1 with GalR from pSA546.

viously showed that (i) binding of LacI repressor to the cognate operator also stimulated $P 2$ and repressed $P 1$, and the nature of the regulation at $P 1$ or $P 2$ depended upon the relative angular orientation of the promoter to $O_{\mathrm{E}}$ (Choy et al., 1995a). To ascertain whether the inhibition of $P 1$ and stimulation of $P 2$ by GalR itself is related to the relative angular orientation of bound RNA polymerase and repressor on the face of DNA, we inserted an extra half of a DNA helical turn (5 bp) between $O_{\mathrm{E}}$ and the promoters. This insertion will change the relative orientation of the two promoters with respect to $O_{\mathrm{E}}$. The results of transcription from this DNA template showed clearly that changing the orientation of the two promoters reversed 
the regulation; GalR repressed $P 2$ and activated $P 1$ (Figure $3 \mathrm{~d}$ ). These results demonstrated that the different regulatory responses of $P 1$ and $P 2$ towards GalR were not the intrinsic properties of the two promoters and depended upon the relative angular orientation of the promoters with respect to $O_{\mathrm{E}}$.

\section{Specific amino acids of the $\alpha$-subunit of RNA polymerase are involved in both activation and repression by GalR}

We previously showed that both activation and repression by $O_{\mathrm{E}}$-bound GalR require an intact $\alpha \mathrm{CTD}$ of the RNA polymerase molecule, suggesting the involvement of $\alpha \mathrm{CTD}$ region in GalR action. This region of the $\alpha$-subunit has been shown to contain segments that presumably interact with DNA and with many DNA-binding activator proteins in activation of transcription at other promoters (Ishihama, 1993; Ebright \& Busby, 1995). Table 1 summarizes the effect of GalR titration $(0$ to $20 \mathrm{nM}$ ) on $P 1$ repression and $P 2$ activation when using RNA polymerases each reconstituted with $\alpha$ subunits carrying a specific amino acid alteration. The results with $\alpha$-subunits containing a tryptophan substitution at positions 265 and 268 to 270 were dramatic; they virtually abolished both repression of $P 1$ and activation of $P 2$. Two other substitutions, alanine and lysine, at position 265 showed the same defect as did the tryptophan substitution at this position. Additionally, tryptophan substitutions at positions 260, 261, 264 and 266 made the respective RNA polymerases partially responsive to GalR-mediated repression of $P 1$ and stimulation of $P 2$. Tryptophan substitution at positions 262, 263 and 267 in $\alpha$ CTD did not alter GalR regulation in a detectable way. These results show that specific amino acid residues in $\alpha$ CTD are involved in both types of GalR regulation.

\section{Formation of GalR- $O_{\mathrm{E}}$-RNA polymerase ternary complex}

DNase protection results showed that GalR enhances open complex formation at $P 2$ and helps RNA polymerase to form a heparin-resistant intermediate between the closed and open forms at P1 (Choy et al., 1995a). These results are easily explained by assuming that the $O_{\mathrm{E}}$-bound GalR is part of the open complex at $P 2$ and part of the intermediate complex at $P 1$. The formation of a ternary complex at each promoter was tested by gel electrophoresis of $P 1^{+} P 2^{-}$or $P 1^{-} P 2^{+}$DNA in the presence of GalR and RNA polymerase under similar conditions. The $104 \mathrm{bp}$ DNA fragments used contained the gal region from -76 to +38 . The binding reactions were carried out in the presence of heparin to inhibit non-specific RNA polymerase binding to DNA. Figure 5 shows the results of RNA polymerase titration of $P 1$ and $P 2$. In the absence of GalR, RNA polymerase formed distinct binary complexes with both $P 1$ (Figure 5a,
Table 1. Effect of GalR bound to $O_{\mathrm{E}}$ on transcription from gal $P 1$ and $P 2$ promoters using reconstituted RNA polymerases carrying different amino acid substitutions at $\alpha \mathrm{CTD}$

\begin{tabular}{lcc}
\hline $\begin{array}{c}\text { Amino acid } \\
\text { substitution in } \alpha \text { CTD }\end{array}$ & $\begin{array}{c}\text { GalR repression } \\
\text { at galP1 }\end{array}$ & $\begin{array}{c}\text { GalR activation } \\
\text { at galP2 }\end{array}$ \\
\hline WT & ++++ & ++++ \\
L260W & ++ & ++ \\
E261W & +++ & +++ \\
L262W & ++++ & ++++ \\
T263W & ++++ & ++++ \\
V264W & +++ & +++ \\
R265W & - & - \\
R265A & - & - \\
R265K & - & - \\
S266W & ++ & ++ \\
A267W & ++++ & ++++ \\
N268W & - & - \\
C269W & - & - \\
L270W & - & -
\end{tabular}

The results of columns 2 and 3 were obtained from the GalR titration experiments with pSA544 similar to that shown in Figure 2. The repression and activation with the reconstituted mutant RNA polymerases at the corresponding promoters were compared with the effect shown with reconstituted wild-type RNA polymerase and expressed as follows: 80 to $100 \%$, $++++; 60$ to $79 \%,+++; 40$ to $59 \%,++; 20$ to $39 \%$, + ; $<20 \%,-$. The amount of transcription from the two gal promoters by the reconstituted RNA polymerases in the absence of GalR were the same within experimental variations. The effect of GalR on $P 1$ repression (column 2) and $P 2$ activation (column 3) with wild-type RNA polymerase were taken as $100 \%$.

lanes 1 to 6 ) and $P 2$ (Figure 5b, lanes 1 to 5). At 20 pM DNA, 200 pM RNA polymerase was needed for the $P 1$ promoter and $100 \mathrm{pM}$ RNA polymerase for the $P 2$ promoter for complete titration: $20 \mathrm{nM}$ GalR was able to saturate the same amount of DNA in the absence of RNA polymerase (Figure 5a, lane 7 and $b$, lane 6). Titration of GalR-saturated DNA by RNA polymerase showed the formation of ternary complexes with characteristic electrophoretic mobilities in the case of both $P 1$ (Figure 5a, lanes 8 to 12) and $P 2$ (Figure $5 b$, lanes 7 to 10$)$. It also appeared that RNA polymerase did not compete with GalR at $P 1$; in the presence of GalR, even 400 pM RNA polymerase did not form the RNA polymerase-DNA binary complex by competing out GalR. On the other hand, GalR increased the affinity of RNA polymerase at the $P 2$ promoter; the half-maximal saturating concentration of RNA polymerase shifted from $60 \mathrm{nM}$ in the absence of GalR to $30 \mathrm{M}$ in the presence of GalR. This is in agreement with the DNase protection results, which showed that open complexes are formed at P2 at lower RNA polymerase concentrations in the presence of GalR (Choy et al., 1995a).

\section{Discussion}

In has been suggested that the regulation of the two gal promoters by GalR occurs by altering the partitioning of RNA polymerase between two overlapping promoters that compete for the enzyme (Goodrich \& McClure, 1992). This model 

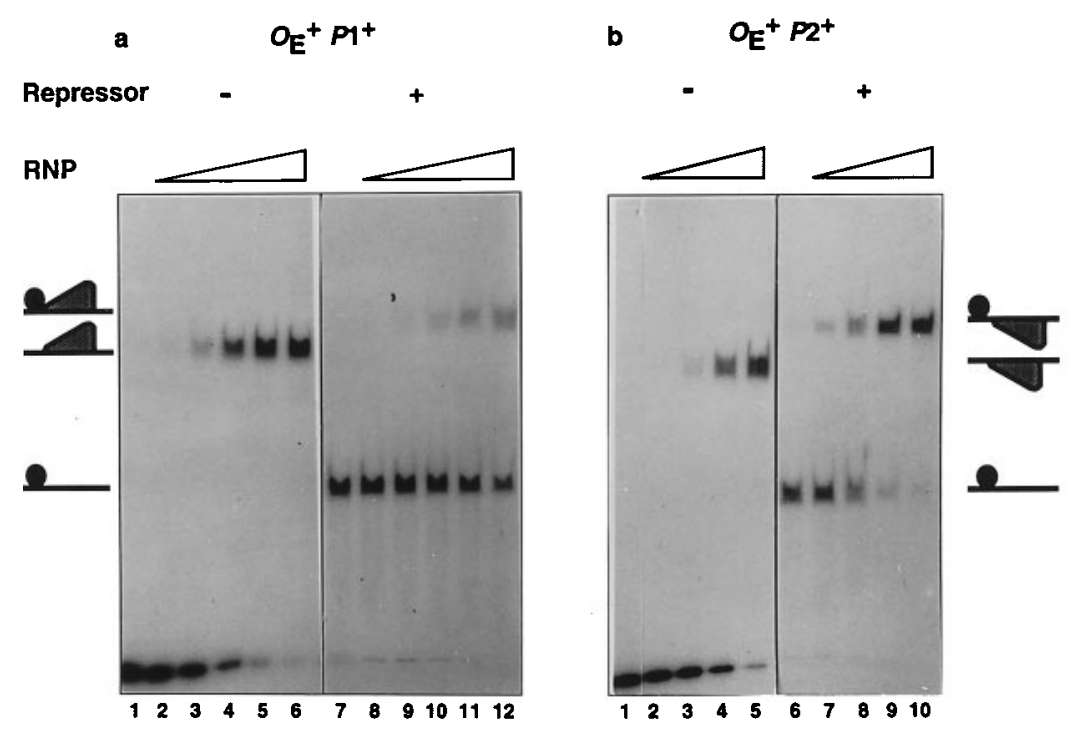

Figure 5. Gel electrophoresis of gal DNA bound to GalR and/or different concentrations of RNA polymerase as described in Materials and Methods. The ${ }^{32}$ P-labeled DNA concentration was 20 pM: $20 \mathrm{nM}$ GalR was needed to completely titrate $50 \mathrm{pM}$ DNA (results not shown). a, $\mathrm{O}_{\mathrm{E}}^{+} \mathrm{P} 2^{-} P 1^{+} \mathrm{O}_{\mathrm{I}}^{-} \quad$ DNA (from plasmid pSA541); b, $\mathrm{O}_{\mathrm{E}}^{+} P 2^{+} P 1^{-} \mathrm{O}_{\mathrm{I}}^{-}$DNA (from plasmid pSA542). The RNA polymerase concentrations were $0,50,100,200$, 400 and $800 \mathrm{pM}$ in lanes 1 to 6 and also in lanes 7 to 12 , respectively (a) and 0, 50, 100, 200 and $400 \mathrm{pM}$ in lanes 1 to 5 and also in lanes 6 to 10 , respectively (b). The different DNA-protein complexes are shown as cartoons on the sides, the filled circles indicating GalR and the shaded triangles indicating RNA polymerase.

predicts that mutation of one promoter would abolish the effect of GalR on the other promoter. We studied the effect of GalR on DNA templates carrying in each case only one active promoter and the other mutated. The results of such mutational studies reported here demonstrated that the dual role of GalR toward $P 1$ and $P 2$ are independent of each other. GalR exerted its specific regulatory effect on each promoter when the other was mutationally inactivated. The fact that GalR stimulated $P 2$ in the absence of $P 1$ and repressed $P 1$ in the absence of $P 2$ suggests that GalR regulates each promoter independently. The results discussed below confirm such an interpretation.

The results of gel electrophoresis of DNA templates carrying only one of the two promoters demonstrate the formation of a ternary complex of RNA polymerase, GalR and DNA at each promoter, and point to a direct role of GalR both in repressing $P 1$ and in enhancing $P 2$. We propose that $O_{\mathrm{E}}$-bound GalR enhances open complex formation at $P 2$ by increasing the affinity of RNA polymerase and inhibits the conversion of closed to open complex at $P 1$ by directly contacting RNA polymerase. Our demonstration of the inability of GalR to show any regulatory effect when transcription reactions were carried out with RNA polymerases carrying specific mutations strongly supports the notion that a protein-protein contact between $O_{\mathrm{E}}$-bound GalR and the $\alpha$ CTD of RNA polymerase is involved in the enhanced binding of RNA polymerase to $P 2$ (cooperative binding) and inactivation of an intermediate complex at $P 1$.

\section{Enhancement of $P 2$}

The finding of GalR enhancement of $P 2$ parallels the activation of transcription of the E. coli lac promoter by cAMP receptor protein (CRP or CAP). $\mathrm{CRP}$ binds to position -61.5 at the lac promoter and helps binding of RNA polymerase by a physical interaction with $\alpha$ CTD (reviewed by Ebright \& Busby, 1995; Heyduk et al., 1993). The contact stabilizes $\alpha$ CTD binding to the DNA segment between the CRP and the rest of RNA polymerase binding sites at the lac promoter. Amino acid substitutions in the interval 258 to 270 in $\alpha$ CTD render the corresponding RNA polymerases poorly responsive or non-responsive to CRP activation at the lac promoter, suggesting that the interval 258 to 270 is involved in $\alpha$ CTD-CRP and/or $\alpha$ CTDDNA interactions important for CRP-dependent transcription (Murakami et al., 1996; Tang et al., 1994). Our results show that substitutions in the same interval render RNA polymerase poorly responsive or non-responsive to GalR at $P 2$, suggesting that this interval is involved in $\alpha C T D-$ GalR and/or $\alpha$ CTD-DNA interactions important for GalR-dependent transcription activation. We emphasize that our results do not distinguish between effects of substitutions on $\alpha$ CTD-GalR interactions and $\alpha$ CTD-DNA interactions. The aCTD is known to occupy the DNA segment centered at position -45 (position -40 with respect to the $P 2$ start site) when RNA polymerase binds to the P2 promoter in gal (Belyaeva et al., 1996). $\alpha \mathrm{CTD}$ binds to a DNA element (up) in rrn promoters in stimulating transcription (Jeon et al., 1995; Murakami et al., 1996; Gaal et al., 1996). We point out, however, that unlike the binding of CRP at position -61.5 at lac, GalR exerts the stimulatory effect by binding to position -60.5 ( -55.5 with respect to the $P 2$ start site) at $P 2$ in gal. This point is further discussed below.

\section{Repression of $\boldsymbol{P 1}$}

Since amino acid alterations that reduce or eliminate $P 2$ activation also reduce or eliminate $P 1$ repression, it is possible that the same contact 
between GalR and/or DNA and the holoenzyme brings about the opposite effects. But unlike the mechanism of transcription enhancement at the $P 2$ promoter by GalR and at the lac promoter by CRP, the inhibition of transcription initiation at $P 1$ by GalR has greater conceptual significance. In contrast to the conventional model of repression, i.e. by inhibition of RNA polymerase binding by repressor owing to competition for binding to overlapping DNA sites (Schlax et al., 1995), $\mathrm{O}_{\mathrm{E}^{-}}$ bound GalR allowed RNA polymerase binding to P1 (Figure 5). A simple competition model predicts the formation of an RNA polymerase-promoter binary complex when the GalR-DNA complex was titrated with RNA polymerase at saturating concentrations of the latter. Starting with the GalRDNA binary complex, we never detected the formation of an RNA polymerase-DNA binary complex when titrated with RNA polymerase to very high concentrations. This suggests that the two proteins do not compete for DNA binding at the $P 1$ promoter. DNase footprinting results showed that RNA polymerase forms a heparinresistant intermediate at $P 1$ when GalR is bound to $O_{\mathrm{E}}$ with a characteristic protection pattern that is different from the one typical of open complexes (Choy et al., 1995a). GalR possibly traps a complex that is an intermediate between a closed and an open complex. Since a higher concentration of RNA polymerase was needed to bind to $P 1$ in the presence than in the absence of GalR, the intermediate complex is less stable than the open complex at $P 1$. Repressor action at a step following the binding of RNA polymerase has been reported for a few other regulators, e.g. the MerR (Frantz \& O'Haloran, 1990; Heltzel et al., 1990) and NagC (Plumbridge, 1995) proteins of E. coli, the SpoA protein of Bacillus subtilis (Greene \& Spiegelman, 1996), the p4 protein of a B. subtilis phage $\phi 29$ (Monsalve et al., 1996a,b) and the Arc protein of Salmonella typhimurium phage P22 (Smith \& Sauer, 1996). Formation of ternary complexes of DNA, RNA polymerase and the regulatory protein have been shown for MerR, SpoOA, p4 and Arc. The SpoOA and Arc proteins appear to prevent open complex formation at a post-RNA polymerase binding step (Greene \& Spiegelman, 1996; Smith \& Sauer, 1996), whereas the p4 protein has been shown to act by blocking the step of promoter clearance; $p 4$ contacts the $\alpha \mathrm{CTD}$ and makes RNA polymerase remain in an abortive RNA synthesis mode (Monsalve et al., 1996b). A ternary complex formation by LacI and RNA polymerase at the E. coli lac promoter suggested earlier (Straney \& Crothers, 1987; Lee \& Goldfarb, 1991) has been questioned recently (Schlax et al., 1995).

Like GalR, the Arc protein of P22 shows opposing regulatory effects at different promoters although it is not known whether Arc acts by contacting RNA polymerase (Smith \& Sauer, 1996). How does a protein have opposite regulatory effects on two promoters by direct contact with RNA polymerase? We have shown that the nature of the control, enhancement or repression, is not the intrinsic property of a given promoter in this system. The face of DNA occupied by RNA polymerase relative to the face of DNA occupied by GalR is the critical determinant; the same face brings about repression, the opposite face causes enhancement. We postulate that the opposite effects of the same $\alpha$ CTD-GalR and/or same GalRdependent $\alpha$ CTD-DNA interaction is because of the difference in the energetics of the steps of the conversion of the free DNA and RNA polymerase to the open complex imposed by the different architectural constraints in the two systems, i.e. the relative geometry of DNA-bound GalR and RNA polymerase as well as the nature of the promoter DNA sequence (Roy \& Adhya, 1997).

\section{Materials and Methods}

\section{Plasmids}

The principle of construction and functional elements of the gal plasmids used in this study have been described (Choy \& Adhya, 1993). Plasmids pSA509, pSA511 and pSA512 contained a $288 \mathrm{bp}$ gal promoter segment (region -197 to +91) and plasmids pSA541, pSA542, pSA544, pSA545, pSA546 and pSA548 contained a 167 bp gal DNA segment (region -76 to +91). Of these, plasmids pSA541 and pSA542 used in the gel electrophoresis experiments have been described (Choy et al., 1995a). The gal DNA in each case was followed by a Rho-independent transcription terminator. The gal genotypes of the plasmids are shown in Table 2 . The $P 1$ and $P 2$ mutations of gal used were a $\mathrm{G}$ to A transition at position -14 and a $T$ to $G$ transversion at position -19 , respectively, and were kindly given by $S$. Busby (Bingham et al., 1986). The galR plasmid has been described (Majumdar \& Adhya, 1984).

\section{Proteins}

GalR was hyperexpressed from a $P_{\mathrm{L}}$-galR fusion plasmid (pAM2) by inducing the bacteriophage $\lambda$ promoter $P_{\mathrm{L}}$ after heat inactivation of a temperature-sensitive prophage repressor (cI857) and then purified as described (Majumdar et al., 1987). Wild-type RNA polymerase was purchased from Pharmacia. Reconstituted RNA polymerases composed of wild-type subunits or of $\alpha$-subunit carrying amino acid substitution at position $261,262,263,264,265,266,267,268,269$ or 270 of its CTD were prepared by Murakami et al. (1996).

Table 2. Plasmids used in in vitro transcription assays

\begin{tabular}{ll}
\hline Plasmid & gal genotype \\
\hline pSA509 & $O_{\mathrm{E}}^{+} P 1^{+} P 1^{+} O_{I}^{+}$ \\
pSA511 & $O_{\mathrm{E}}^{+} P 2^{+} P 1^{+} O_{\mathrm{I}}^{-}$ \\
pSA512 & $O_{\mathrm{E}}^{-} P 2^{+} P 1^{+} O_{\mathrm{I}}^{+}$ \\
pSA541 & $O_{\mathrm{E}}^{+} P 2^{-} P 1^{+} O_{\mathrm{I}}^{+}$ \\
pSA542 & $O_{\mathrm{E}}^{+} P 2^{+} P 1^{-} O_{\mathrm{I}}^{+}$ \\
pSA544 & $O_{\mathrm{E}}^{+} P 2^{+} P 1^{+} O_{\mathrm{I}}^{-}$ \\
pSA545 & $O_{\mathrm{E}}^{+} P 2^{-} P 1^{+} O_{\mathrm{I}}^{-}$ \\
pSA546 & $O_{\mathrm{E}}^{+} P 2^{+} P 1^{-} O_{\mathrm{I}}^{-}$ \\
pSA548 & $O_{\mathrm{E}}^{+}-(5 \mathrm{bp})-P 2^{+} P 1^{+} O_{\mathrm{I}}^{+}$ \\
\hline
\end{tabular}




\section{Transcription assays}

Transcription reactions were carried out as described (Choy \& Adhya, 1993). Briefly, 2 nM supercoiled plasmid DNA template, $1 \mathrm{mM}$ ATP, $0.1 \mathrm{mM}$ GTP, $0.1 \mathrm{mM}$ CTP, $0.01 \mathrm{mM}$ UTP and 10 to $20 \mu \mathrm{Ci}$ of $\left[\alpha^{-32} \mathrm{P}\right] \mathrm{UTP}$ were preincubated in buffer $(20 \mathrm{mM}$ Tris-acetate $(\mathrm{pH} 7.8)$, $10 \mathrm{mM}$ magnesium acetate, $100 \mathrm{mM}$ potassium glutamate) at $37^{\circ} \mathrm{C}$ for five minutes. When present, GalR was included in the preincubation mixture at the concentrations given in the Figure legends. Transcription was initiated by the addition of RNA polymerase $(20 \mathrm{nM})$ in a total volume of $50 \mu \mathrm{l}$ and was terminated after ten minutes at $37^{\circ} \mathrm{C}$ by the addition of an equal volume $(50 \mu \mathrm{l})$ of RNA loading buffer $(80 \%(\mathrm{v} / \mathrm{v})$ deionized formamide, TBE buffer $(89 \mathrm{mM}$ Tris, $89 \mathrm{mM}$ boric acid, $2 \mathrm{mM}$ EDTA), $0.025 \%(\mathrm{w} / \mathrm{v})$ bromophenol blue, $0.025 \%(\mathrm{w} / \mathrm{v})$ xylene cyanole). The mixture was heated at $90^{\circ} \mathrm{C}$ for two minutes and electrophoresed in $8 \mathrm{M}$ urea/8\% (w/v) polyacrylamide sequencing gels. The gal RNA transcripts were quantified by a $\beta$-scanner and normalized with respect to control RNA1 transcript made from the rep promoter present in the templates (PhosphoImager, Molecular Dynamics, CA).

\section{Gel electrophoresis of DNA-protein complexes}

The experiments were carried out essentially as described (Majumdar \& Adhya, 1984): 50 pM ${ }^{32}$ P-labeled $X b a \mathrm{I}-B s t$ EII DNA fragment $(113 \mathrm{bp})$ of gal DNA from pSA541 and pSA542 were incubated in $50 \mu \mathrm{l}$ of reaction buffer (20 mM Tris-acetate ( $\mathrm{pH} 7.8), 10 \mathrm{mM}$ magnesium acetate, $200 \mathrm{mM}$ potassium glutamate, $1 \mathrm{mM}$ DTT, 5\% $(\mathrm{v} / \mathrm{v})$ glycerol) in the absence or presence of $20 \mathrm{nM}$ repressor. After ten minutes at $37^{\circ} \mathrm{C}$, RNA polymerase was added and incubated for an additional ten minutes. Heparin was added to a final concentration of $50 \mu \mathrm{g} / \mathrm{ml}$ and the entire reaction mixture was electrophoresed on a $4 \%$ polyacrylamide gel in TBE buffer for three hours.

\section{Acknowledgments}

We thank Mark Geanacopoulos, Dale Lewis, Sue Garges and Siddhartha Roy for valuable discussions, Thomas Soares for technical assistance, Steve Busby for the gift of gal promoter mutants, and Althea Jackson for editorial assistance.

\section{References}

Adhya, S. (1989). Multipartite genetic control elements: communication by DNA loop. Annu. Rev. Genet. 23, $227-250$

Aki, T. \& Adhya, S. (1997). Repressor induced sitespecific binding of $\mathrm{HU}$ for transcriptional regulation. EMBO J. 16, 3666-3674.

Aki, T., Choy, H. E. \& Adhya, S. (1996). Histone-like protein $\mathrm{HU}$ as a specific transcriptional regulator: co-factor role in repression of gal transcription by Gal repressor. Genes Cells, 1, 179-188.

Belyaeva, T. A., Bown, J. A., Fujita, N., Ishihama, A. \& Busby, S. J. W. (1996). Location of the C-terminal domain of the RNA polymerase alpha subunit in different open complexes at the Escherichia coli galactose operon regulatory region. $\mathrm{Nucl}$. Acids Res. 24, 2242-2251.
Bingham, A. H. A., Ponnabalam, S., Chan, B. \& Busby, S. (1986). Mutations that reduce expression from the P2 promoter of the Escherichia coli galactose operon. Gene, 41, 67-74.

Choy, H. E. \& Adhya, S. (1992). Control of gal transcription through DNA looping: inhibition of the initial transcribing complex. Proc. Natl Acad. Sci. USA, 89, 11264-11268.

Choy, H. E. \& Adhya, S. (1993). RNA polymerase idling and clearance in gal promoters: use of supercoiled minicircle DNA template made in vivo. Proc. Natl Acad. Sci. USA, 90, 472-476.

Choy, H. \& Adhya, S. (1996). Negative control. In Cellular and Molecular Biology: Escherichia coli and Salmonella typhimurium (Neidhardt, F. M., et al., eds), pp. 1287-1299, American Society for Microbiology, Washington, DC.

Choy, H. E., Park, S.-W., Aki, T., Parrack, P., Fujita, N., Ishihama, A. \& Adhya, S. (1995a). Repression and activation of transcription by Gal and Lac repressors: involvement of alpha subunit of RNA polymerase. EMBO J. 14, 4523-4529.

Choy, H. E., Park, S.-W., Parrack, P. \& Adhya, S. (1995b). Transcription regulation by inflexibility of promoter DNA in a looped complex. Proc. Natl Acad. Sci. USA, 92, 7327-7331.

Ebright, R. E. \& Busby, S. (1995). The Escherichia coli RNA polymerase alpha subunit: structure and function. Curr. Opin. Genet. Dev. 5, 197-203.

Frantz, B. \& O'Haloran, T. V. (1990). DNA distortion accompanies transcriptional activation by the metalresponsive gene-regulatory protein MerR. Biochemistry, 29, 4747-4751.

Gaal, T., Ross, W., Blatter, E. E., Tang, H., Jia, X., Krishnan, V. V., Assa-Munt, N., Ebright, R. H. \& Gourse, R. L. (1996). DNA-binding determinants of the alpha subunit of RNA polymerase: novel DNAbinding domain architecture. Genes Dev. 10, 16-26.

Goodrich, J. A. \& McClure, W. R. (1992). Regulation of open complex formation at the Escherichia coli galactose operon promoters. Simultaneous interaction of RNA polymerase, gal repressor and CAP/cAMP. J. Mol. Biol. 224, 15-29.

Greene, E. A. \& Spiegelman, G. B. (1996). The SpoOA protein of Bacillus subtilis inhibits transcription of the abrB gene without preventing binding of the polymerase to the promoter. J. Biol. Chem. 271, 11455-11461.

Heltzel, A., Lee, I. W., Totis, P. A. \& Summers, A. O. (1990). Activator-dependent preinduction of sigma70 RNA polymerase at the metal-regulated mer promoter. Biochemistry, 29, 9572-9584.

Heyduk, T., Lee, J., Ebright, Y., Blatter, E., Zhou, Y. \& Ebright, R. (1993). CAP interacts with RNA polymerase in solution in the absence of promoter DNA. Nature, 364, 548-549.

Ishihama, A. (1993). Protein-protein communication within the transcription apparatus. J. Bacteriol. 175, 2483-2489.

Jeon, Y. H., Negishi, T., Shirakawa, M., Yamazaki, T., Fujita, N., Ishihama, A. \& Kyogoku, Y. (1995). Solution structure of the activator contact domain of the RNA polymerase alpha subunit. Science, 270, 1495-1497.

Lee, J. \& Goldfarb, A. (1991). lac repressor acts by modifying the initial transcribing complex so that it cannot leave the promoter. Cell, 66, 793-798. 
Li, M., Moyle, H. \& Susskind, M. M. (1994). Target of the transcriptional activation function of phage lambda cI protein. Science, 263, 75-77.

Majumdar, A. \& Adhya, S. (1984). Demonstration of two operator elements in gal: in vitro repressor binding studies. Proc. Natl Acad. Sci. USA, 81, 61006104.

Majumdar, A. \& Adhya, S. (1987). Probing the structure of Gal operator-repressor complexes: conformation change in DNA. J. Biol. Chem. 262, 13258-13262.

Majumdar, A. \& Adhya, S. (1989). Effect of ethylation of operator-phosphates on Gal repressor binding. DNA contortion by repressor. J. Mol. Biol. 208, 217223.

Majumdar, A., Rudikoff, S. \& Adhya, S. (1987). Purification and properties of Gal repressor: pL-galR fusion in PKC 31 plasmid vector. J. Biol. Chem. 262, 2326-2331.

Monsalve, M., Mencia, M., Rojo, F. \& Salas, M. (1996a). Activation and repression of transcription at two different phage ph129 promoters are mediated by interaction of the same residues of regulatory protein p4 with RNA polymerase. EMBO J. 15, 383391.

Monsalve, M., Mencia, M., Salas, M. \& Rojo, F. (1996b). Protein p4 represses phage phi 29 A2c promoter by interacting with the alpha subunit of Bacillus subtilis RNA polymerase. Proc. Natl Acad. Sci. USA, 93, 8913-8918.
Murakami, K., Fujita, N. \& Ishihama, A. (1996). Transcription factor recognition surface on the RNA polymerase alpha subunit is involved in contact with the DNA enhancer element. EMBO J. 15, $4358-4367$.

Plumbridge, J. (1995). Coordinated regulation of amino sugar biosynthesis and degradation: the NagC repressor acts as both an activator and a repressor for the transcription of the glmUS operon and requires two separated NagC binding sites. EMBO J. 14, 3958-3965.

Roy, S. \& Adhya, S. (1997). Mechanism of activation of transcription initiation in prokaryotes. In Transcription (Hawley, D. \& Burton, M., eds), Chapman and Hall, in the press.

Schlax, P. J., Capp, M. W. \& Record, M. T., Jr (1995). Inhibition of transcription initiation by lac repressor. J. Mol. Biol. 245, 331-350.

Smith, T. L. \& Sauer, R. T. (1996). Dual regulation of open-complex formation and promoter clearance by Arc explains a novel repressor to activator switch. Proc. Natl Acad. Sci. USA, 93, 8868-8872.

Straney, S. B. \& Crothers, D. M. (1987). Lac repressor is a transient gene-activating protein. Cell, 51, 699707.

Tang, H., Severinov, K., Goldfarb, A., Fenyo, D., Chait, B. \& Ebright, R. H. (1994). Location, structure and function of the target of a transcriptional activator protein. Genes Dev. 8, 3058-3067.

Edited by R. Ebright

(Received 3 April 1997; received in revised form 13 June 1997; accepted 13 June 1997) 